\title{
Landscape Connectivity as a Function of Scale and Organism Vagility in a Real Forested Landscape
}

\author{
$\underline{\text { Robert G. D'Eon }}^{1}, \underline{\text { Susan M. Glenn }}{ }^{2}, \underline{\text { Ian Parfitt }}^{3}$, and Marie-Josée Fortin ${ }^{4}$
}

\begin{abstract}
Landscape connectivity is considered a vital element of landscape structure because of its importance to population survival. The difficulty surrounding the notion of landscape connectivity is that it must be assessed at the scale of the interaction between an organism and the landscape. We present a unique method for measuring connectivity between patches as a function of organism vagility. We used this approach to assess connectivity between harvest, old-growth, and recent wildfire patches in a real forested landscape in southeast British Columbia. By varying a distance criterion, habitat patches were considered connected and formed habitat clusters if they fell within this critical distance. The amount of area and distance to edge within clusters at each critical distance formed the basis of connectivity between patches. We then assessed landscape connectivity relative to old-growth associates within our study area based on species' dispersal abilities. Connectivity was greatest between harvest patches, followed by old-growth, and then wildfire patches. In old-growth patches, we found significant trends between increased connectivity and increased total habitat amount, and between decreased connectivity and increased old-growth harvesting. Highly vagile old-growth associates, such as carnivorous birds, perceive this landscape as connected and are able to access all patches. Smaller, less vagile species, such as woodpeckers, chickadees, and nuthatches, may be affected by a lack of landscape connectivity at the scale of their interaction with old-growth patches. Of particular concern is the northern flying squirrel (Glaucomys sabrinus), which we predict is limited in this landscape due to relatively weak dispersal abilities.
\end{abstract}

\section{INTRODUCTION}

Habitat fragmentation is one of the most commonly cited threats to species extinction and an ensuing loss of biological diversity, making it perhaps the most important contemporary conservation issue (Wiens 1996). Lord and Norton (1990) referred to fragmentation as simply the disruption of continuity. The inverse of landscape fragmentation, landscape connectivity is considered a vital element of landscape structure (Taylor et al. 1993) because it is so critical to population survival (Fahrig and Merriam 1985, Fahrig and Paloheimo 1988) and metapopulation dynamics (Levins 1970).

Landscape connectivity can be defined as the degree to which the landscape facilitates or impedes movement between resources patches (Taylor et al. 1993). A direct measure of landscape connectivity, therefore, must incorporate a measure of some aspect of organism movement through the landscape. Fahrig and Paloheimo (1988) and Henein and Merriam (1990) measured connectivity as the probability of movement between two resources patches, using mathematical models of animal movements. Two other common measures of landscape connectivity are dispersal success and search time: the first is defined as the immigration rate of an organism into resources patches, the latter as the time spent in transit between resources patches. Tishendorf and Fahrig (2000a) point out the weakness of these measures in that higher values of connectivity (high immigration, and low search time) ironically result from more fragmented landscapes (i.e., a greater number of smaller patches in a landscape results in higher patch interception rates, and thereby immigration, and lower search times indicating, by definition, greater landscape connectivity). As a way of overcoming this problem, they advocate measuring cell immigration (dividing patches into equal-sized cells and measuring the rate of immigration into cells-thereby including movement inside a large patch, between cells).

Although methods such as these measure animal movement parameters directly, and are possible in simulation and modeling work, they are often

\footnotetext{
${ }^{1}$ Department of Forest Sciences, University of British Columbia; ${ }^{2}$ Science Division, Gloucester County College; ${ }^{3}$ Ian Parfitt Biogeographics, $\mathrm{BC} ;{ }^{4}$ Department of Zoology, University of Toronto
} 
impossible or impractical to use in empirical studies, despite Tishendorf and Fahrig's (2000a) assertion that measuring movement rates on even $1 \%$ of a landscape is sufficient to assess landscape connectivity (but see Arnold et al. (1993) and Pither and Taylor (1998)). Indeed, in a review of connectivity research, Tishendorf and Fahrig (2000b) found only four studies that measured landscape connectivity directly, and all four used modeling approaches. As well, although percolation theory, the study of connectivity in stochastically generated structures (Stauffer and Aharony 1985), has been useful when applied in the development of a generalized, spatially explicit, theoretical framework (With 1997), its applications in empirical work are currently limited (but see Keitt et al. (1997)).

As Tishendorf and Farhig (2000b) concede, in most practical management applications, directly measuring connectivity by measuring animal movement and ensuing rates within landscapes is not feasible for logistical reasons. As a result, most work on real landscapes to quantify landscape connectivity has focused on landscape indices that characterize the spatial pattern of a landscape as surrogates for direct measurements of connectivity. The indices are then interpreted and conclusions are drawn regarding landscape connectivity. Although literally hundreds of landscape indices have been derived and used (Gustafson 1998), the generalization of relationships between landscape indices and ecological processes reflecting landscape connectivity is poorly understood (Tishendorf 2001). This is, no doubt, due to the static nature of the landscape indices that typically characterize spatial configuration of patches and landscapes from a non-organismal perspective and under one set of rules (e.g., habitat availability does not change). As a result, most landscape indices reflect spatial patterns under one set of circumstances, and are usually not linked to any specific organism movement through the landscape.

Taking a somewhat more robust perspective, landscape connectivity can refer to the functional linkage between habitat patches, either because habitat is connected through structural continuity or because dispersal abilities permit organisms to travel between discrete patches and, therefore, perceive patches as functionally connected (With et al. 1997). In the latter case, organism vagility is one of the most important determinants of landscape connectivity and is why many researchers advocate an organismal perspective when addressing landscape connectivity (Wiens 1989,
Schumaker 1996, With et al. 1997, Tishendorf and Fahrig 2000a, b). Taking this view then, landscape connectivity must be considered at the scale of the interaction between an organism and the landscape. Thus, a landscape is not inherently fragmented or connected, but can only be assessed in the context of an organism's ability to move between patches and the scale at which the organism interacts with the landscape (Davidson 1998, With 1999). As well, many ecologists predict non-linear patterns in connectivity, suggesting thresholds or abrupt changes in landscape connectivity exist and are scale dependent (With and Crist 1995, Keitt et al. 1997). If true, connectivityinduced consequences to species living in landscapes should be predictable and relative to species vagility, the scale of interactions between an organism and the landscape, and connectivity thresholds.

Commercial forest harvesting is commonly presented as a primary cause of forest fragmentation or of a disruption in continuity (Franklin and Forman 1987, McGarigal et al. 2001). As forests are harvested, distances between remnant patches may increase and may represent a reduction in connectivity. However, connectivity is reduced in these cases only if an organism's ability to move between suitable habitat patches is reduced, underscoring the importance of an organismal perspective. We assessed landscape connectivity across multiple scales based on a range of critical distances representing the movement capabilities of selected species. We built upon the approach taken by Keitt et al. (1997) to provide a generalized measure of connectivity for use with forest-cover information in vector format at the scale of forest management. We performed our analyses using publicly available forest-cover data derived from real managed forest landscapes in southeastern British Columbia. Our objectives were to: (1) derive a multiscale measure of landscape connectivity related to organism vagility, (2) detect critical connectivity thresholds in real landscapes, (3) test a hypothesis that commercial forest harvesting reduces connectivity between old-growth patches, and (4) predict consequences to selected species related to landscape connectivity in these landscapes.

\section{METHODS}

\section{Landscape delineation}

Digital forest-cover data obtained from the British Columbia Ministry of Forests (Castlegar, British Columbia) were derived from a managed forest 
landscape of 362350 ha within the Slocan Valley of the Selkirk mountains in southeast British Columbia, Canada $\left(49^{\circ} \mathrm{N}, 117^{\circ} \mathrm{W}\right.$; Fig. 1). Forest-cover classification was provided in vector format and derived from interpretation of 1:20000 black and white aerial photographs. Terrain within this mountainous area is generally steep and broken, with slope gradients often exceeding $80 \%$. Elevation ranges from $525 \mathrm{~m}$ along the Slocan Valley bottom to $2800-\mathrm{m}$ mountain peaks.

Fig. 1. Harvest, old-growth, and recent wildfire patches within the Slocan Valley Basin of southeast British Columbia, September 2001.

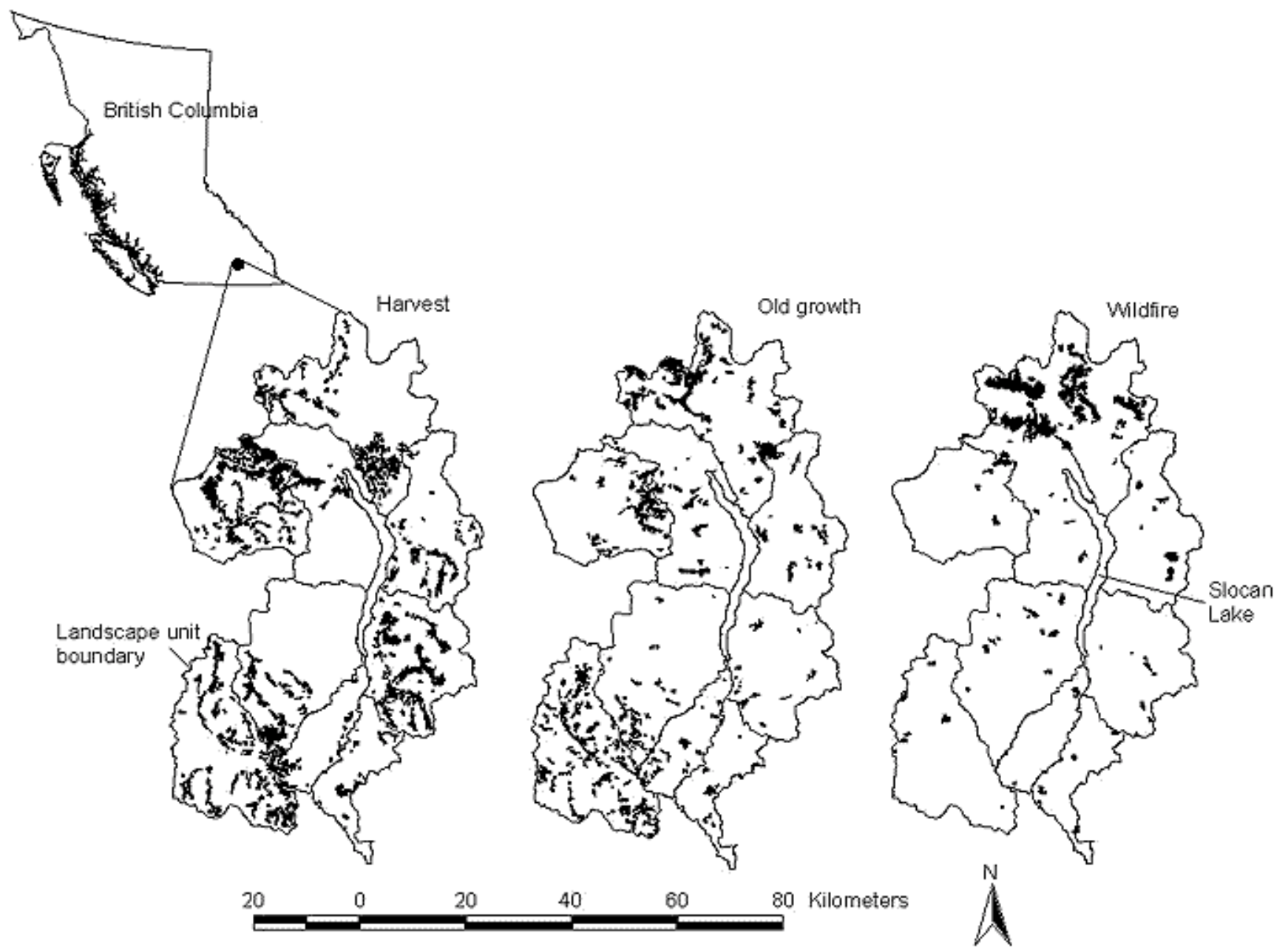

Forested land makes up $71.5 \%$ of the study area. Forests in the study area are within the "Interior Subalpine" and "Southern Columbia" regions described by Rowe (1972) and fall predominantly within three forest biogeoclimatic subzones described by Braumandl and Curran (1992): Interior Cedar Hemlock Dry Warm subzone at low elevations, Interior Cedar Hemlock Moist Warm subzone at mid elevations, and Englemann Spruce Subalpine Fir subzone at higher elevations. Alpine parkland predominates above 2000-m elevations.
Logging within the Slocan Valley began in the late 1800 s but was primarily confined to localized selective harvesting. Large-scale commercial logging began around 1950. Side drainages of the Slocan Valley have since been managed for forest harvesting and road building to varying degrees. Many areas within the main valley corridor and a large provincial park, however, have been excluded from forest harvesting. Most of the low-elevation areas along the main valley bottom are on privately owned land and have been partially deforested for agricultural and urban- 
development purposes. Private land was excluded from the analyses. Routine forest-fire suppression in the area began in the late 1930s (J. Parminter, unpublished data, BC Ministry of Forests, Victoria, British Columbia).

To investigate general connectivity trends across the entire study area, we considered it as a single landscape and performed analyses on this basis. As well, we investigated relationships between varying forest-harvest levels and old-growth connectivity within the study area by comparing connectivity between nine landscape units(LU' as defined by the BC Ministry of Forests) making up the study area (Fig. 1). Landscape units ranged from 18014 to 58858 ha $(<$ mean $>=40261$ ha, SE $=4699$ ha $)$ and were delineated using watershed boundaries primarily.

\section{Distance to edge (DTE_L) calculations}

We reclassified forest-cover data into three patch types within landscapes: harvest patches (clearcuts harvested within the past 40 years), old-growth patches (forest stands >140 years for Interior Cedar Hemlock Dry Warm stands and $>250$ years for all others; old-growth definitions consistent with those issued by the $\mathrm{BC}$ Ministry of Forests and BC Ministry of Environment, Lands and Parks [1995]), and wildfire patches (wildfire within the past 40 years). We then analyzed habitat connectivity using these three patch types separately in a binary manner, where each patch type was considered habitat and all remaining landscape was considered non-habitat. In this way, each patch type was considered separately where patches of habitat were dispersed within a matrix of non-habitat (Fig. 1).

Within an ARCINFO GIS platform, we calculated the edge-to-edge distance between patches of the same patch type. We used the notion of a critical distance representing an organism's ability to travel between habitat patches as a fundamental element of landscape connectivity. Patches within a critical distance were considered connected and formed a habitat cluster. We varied critical distance from $100 \mathrm{~m}$ to the minimum critical distance, where all patches in the landscape became connected into one cluster. We defined the boundary of each cluster as the $100 \%$ mean convex polygon (MCP) boundary surrounding outside patches in the cluster (Fig. 2). As a MCP boundary such as this creates points within the polygon beyond the critical distance from the centroid, boundaries were modified to follow a buffer around patches equal to the critical distance where this occurred. In this way, cluster boundaries were created that encircled all patches in the cluster and ensured all locations within the cluster were within the critical distance to a patch.

Fig. 2. An example of an old-growth habitat cluster illustrating old-growth habitat patches (shaded) and the cluster boundary (outer line). Also shown are 36 lines radiating from the cluster centroid that were used to calculate a mean distance to cluster edge (DTE_C). In this example, there are 38 old-growth patches at a critical distance of $1000 \mathrm{~m}$ forming a 7009-ha cluster with a DTE_C $=4980 \mathrm{~m}$.

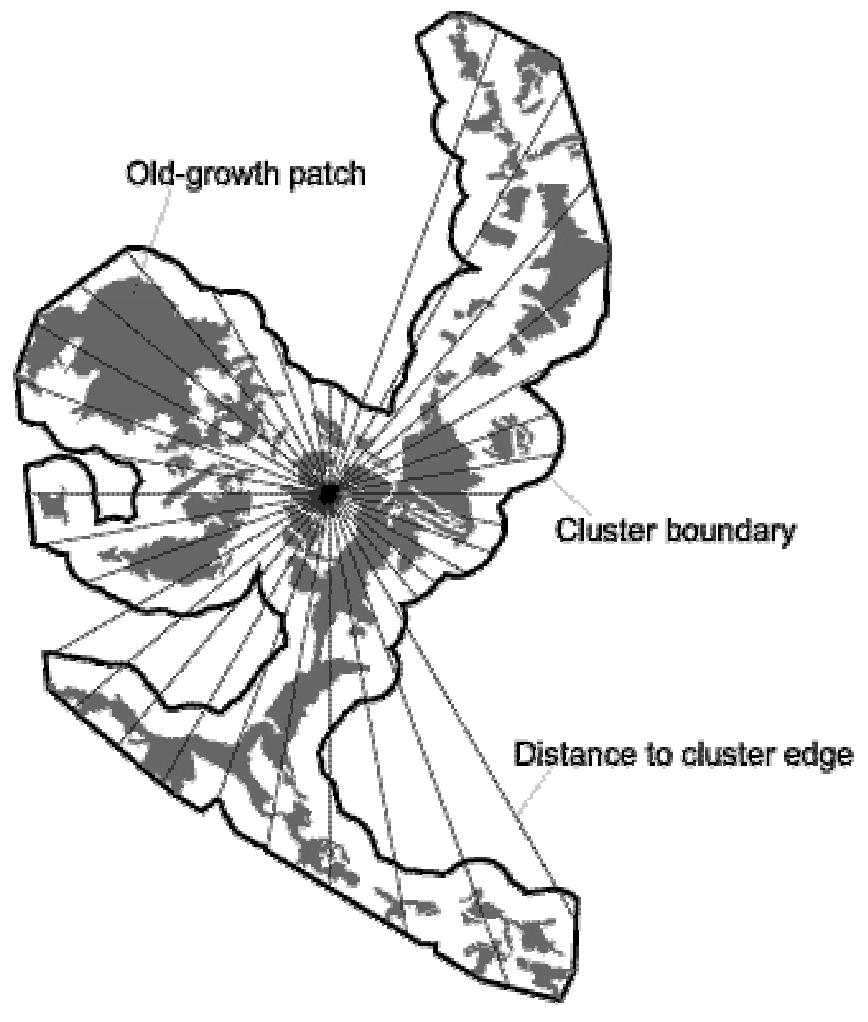

We determined the centroid of each cluster and forced centroids into the cluster in cases where the calculated centroid fell outside of the cluster (this can occur with geometric shapes similar to a "C" or "L"). From the centroid, we projected 36 lines to the cluster boundary at $10^{\circ}$ increments (Fig. 2). We calculated the mean distance of these lines, which represented the mean distance to a cluster edge (DTE_C). At each critical distance, we calculated the mean distance to cluster edges within a landscape (DTE_L) as the mean DTE_C for all clusters within the landscape. We considered DTE_L to be a measure of the average distance an organism could move within a landscape within its habitat type (i.e., for a given patch type), 
given an ability to travel between habitat patches equal to the critical distance. In doing so, we recognize the assumption of a simplistic binary landscape model that forces the following major assumptions: all patches of habitat and non-habitat are equally suitable, travel routes between patches are linear, the only barrier to movement between patches is distance, and all species have equal gap-crossing abilities.

\section{Connectivity measures and trends}

We used the slope of the linear regression model between the critical distance and the logarithmic transformation of the corresponding DTE_L as a measure of overall landscape connectivity for a given patch type and landscape. The slope of this line $(\delta)$ is predictably higher in landscapes with greater patch connectedness because steeper slopes represent more habitat access (DTE_L) for each incremental rise in dispersal ability (critical distance). The opposite is also true in that lower slope values represent landscapes where incremental increases in dispersal ability return lower increases in available habitat, to the extreme case of a flat line (slope $=\delta=0$ ), where increases in dispersal ability do not provide any increase in available habitat. We then used linear and curvilinear regression analyses between $\delta$ and old-growth amount and harvest rates among LUs to investigate connectivity trends relative to harvest rates.

We calculated LU harvest rates (HR) as the amount of harvested area in a landscape $(\mathrm{H})$ divided by the amount of old growth (OG) and harvested area combined (i.e., $\mathrm{HR}=\mathrm{H} /(\mathrm{H}+\mathrm{OG})^{*} 100 \%$ ). We added existing harvested area to existing old-growth area in the denominator of this calculation because we wanted to calculate the old-growth harvest rate as a function of all old-growth forests existing before the onset of commercial logging in the study area. In doing so, we assumed that all recent harvesting (i.e., since 1961) was old-growth harvesting. We believe this to be justifiable, given British Columbia's long-standing policy and tradition of harvesting the oldest forests first. It is also congruent with observable harvest patterns in the study area that tend to target older forests.

\section{Species associations}

We investigated connectivity primarily between oldgrowth patches and vertebrates associated with oldgrowth forest because of the relative importance of old-growth forest to conservation. From an original list of 74 old-growth associates known to occur in our study area (Bunnell 2000), we focused on the northern goshawk (Accipiter gentiles), marten (Martes americana), and cavity-nesting birds and mammals (Table 1). We excluded species associated primarily with riparian old-growth forest (e.g., amphibians and cavity-nesting waterfowl) and more generalist species (e.g., red squirrel [Tamiasciurus hudsonicus]), and concentrated on species with documented dependencies on terrestrial old-growth forest structures, particularly for reproductive habitat.

Although distance between patches is a prime determinant of landscape connectivity, patch size could impact many species, in that only patches large enough to provide suitable resources for an organism would be considered part of its available or connected habitat (With 1999). To investigate this phenomenon, we considered minimum patch-size requirements (MPSR) for individual species. We defined MPSR by building upon Allen (1987) as the minimum amount of contiguous habitat forming a patch, required before a patch can be used or occupied by a species.

For most species, however, a minimum patch size is either not required, unknown, or not consistently demonstrated with data (see Bunnell et al. 1999 for review). Therefore, we used 2 ha as a general MPSR to assess landscape connectivity for most species because it is in the range suggested as a suitable resolution for a large suite of species, including most forest passerines and forest-dwelling small mammals (With 1999), and because it was the finest resolution in our source data. Two old-growth associates in our study area, however, the northern goshawk and the marten, have sufficiently documented data on MPSRs that we felt comfortable assigning them specific MPSRs. The northern goshawk is a forest-dwelling raptor that nests in the study area and has a high association with old forests for nesting (Graham et al. 1999). We assigned a 12-ha MPSR for the northern goshawk based on Reynolds et al.'s (1992) forest management recommendation for nest site reserves. Similarly, we assigned a 15-ha MPSR for marten based on data and recommendations reported by Snyder and Bissonette (1987) and Chapin et al. (1998).

To investigate the consequences of species dispersal ability and patch connectivity, we estimated median and probable maximum dispersal distances for individual species using data and methods provided by Sutherland et al. (2000). Using these estimates, we calculated the amount of the landscape accessible to 
species as a function of dispersal ability by calculating the total amount of cluster area available as a proportion of the landscape area at each critical distance.

\section{Statistical analyses}

Linear and curvilinear regression analyses and student's $t$-tests were performed using SYSTAT 8.0 (SPSS 1998) statistical software. Tests were considered significant at $\alpha=0.05$. Non-normal data distributions were assessed using skewness and kurtosis indicators and transformed using logarithmic transformations to produce more normal distributions. Skewness or kurtosis were considered extreme if \pm 2 times their standard error did not include zero (SPSS 1998).

Fig. 3. Patch size frequency distributions for harvest, oldgrowth, and wildfire patches in the Slocan Valley Basin of southeast British Columbia, September 2001.

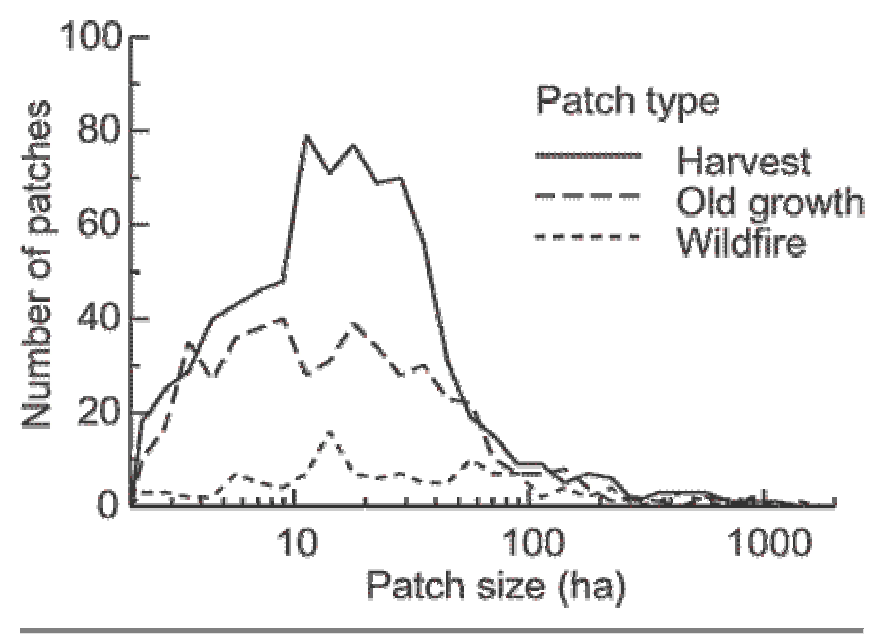

\section{RESULTS}

All three patch types displayed a predictable negative exponential patch size distribution (Fig. 3). Harvest patch sizes $(<$ mean $>=32.8$ ha, $\mathrm{SE}=2.76, n=785$, range $=2.0-1018.4)$ were similar $(t=0.672, P=$ $0.501)$ to old-growth patch sizes $(<$ mean $>=30.0$ ha, $\mathrm{SE}=2.81, n=481$, range $=2.1-787.8)$, but smaller $(t$ $=3.126, P=0.002)$ than wildfire patches ( $<$ mean $>=$ 84.3 ha, $\mathrm{SE}=16.24, n=123$, range $=2.2-1336.6)$. Total patch areas for harvest, old-growth, and wildfire patches were 25771, 14448 , and 10372 ha, respectively.
Fig. 4. Top: Critical distance (CD) versus mean distance to edge (DTE_L) for harvest, old-growth, and wildfire patches within a 325 350-ha landscape in the Slocan Valley of southeast British Columbia. The dashed line represents a 1:1 ratio between DTE_L and $\mathrm{CD}$, where points above the line represent DTE_L/CD > 1.0, and below the line DTE_L/CD < 1.0. Bottom: CD versus DTE_L (logarithm transformed) illustrating linear regression models. Regression equations for harvest patches: $\mathrm{y}=0.2586 \mathrm{x}+2.817, R^{2}=0.923, P<$ 0.001 ; old-growth patches: $\mathrm{y}=0.2163 \mathrm{x}+2.6935, R^{2}=$ $0.986, P<0.001$; wildfire patches: $\mathrm{y}=0.1693 \mathrm{x}+2.5925, R^{2}$ $=0.959, P<0.001$. The slopes of regression models were used as an index of landscape connectivity $(\delta)$ varying between 0 and 1.0, where high values of $\delta$ represent high connectivity among patches. All slopes $(\delta)$ significantly different (test of slope homogeneity: $t=8.036, P<0.001$ ).
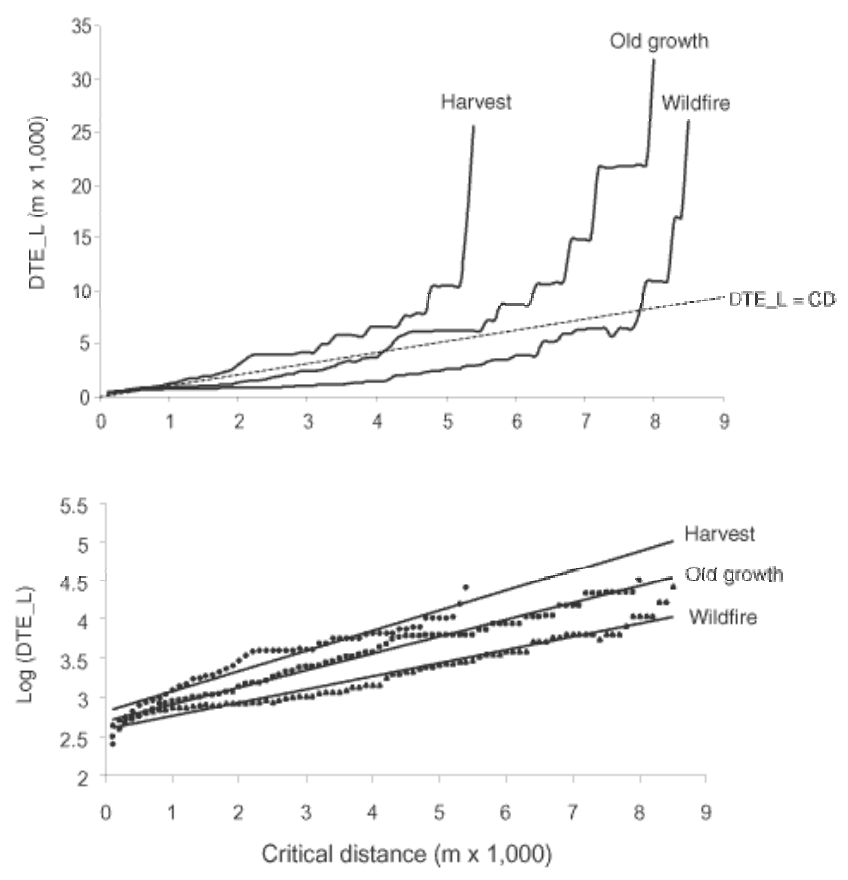

At MPSR $=2$ ha, harvest patches had the highest index of connectivity $(\delta=0.259)$ considering the entire study area as one landscape, followed by old-growth patches $(\delta=0.216)$, and wildfire patches $(\delta=0.169$; Fig. 4 ; slopes significantly different [test of slope homogeneity: $t=8.036, P<0.001])$. At MPSR $=12$ ha, connectivity of old-growth patches within the entire study area was reduced to $\delta=0.206$ and to $\delta=$ 0.204 at MPSR $=15$ ha. Loglinear regression $R^{2}$ for critical distance (CD) versus DTE_L were high $(\geq 0.923)$ and all regressions were highly significant $(P$ $<0.001)$ in these cases and, therefore, considered good fits of the data for comparing slopes (Fig. 4). 
We identified two types of critical threshold in our data. The first is the minimum $\mathrm{CD}$ where all patches became connected and created one large habitat cluster (MIN_CD). This threshold, at MPSR $=2$ ha, occurred at $\mathrm{CD}=5400,8000$, and $8500 \mathrm{~m}$, for harvest, oldgrowth, and wildfire patches respectively (Fig. 4). Between individual LUs at MPSR $=2$ ha, MIN_CD ranged from 2900 to $9400 \mathrm{~m}(<$ mean $>=6311 \mathrm{~m}, \overline{\mathrm{SE}}=$ 718.5 ha, $n=9$ ). Final cluster sizes for harvest, oldgrowth, and wildfire patches were 208568,345 500, and 216965 ha, respectively.

Fig. 5. Critical distance (CD) versus DTE_L/CD curves for nine landscape units in the Slocan Valley of southeastern British Columbia. The dashed line at DTE_L/CD $=1$ is the threshold where mean distance to cluster edge, an index of habitat availability, is equal to critical distance, a measure of dispersal ability. Labels a to $\mathrm{d}$ are landscape units where DTE_L/CD > 1.0 at some CD.

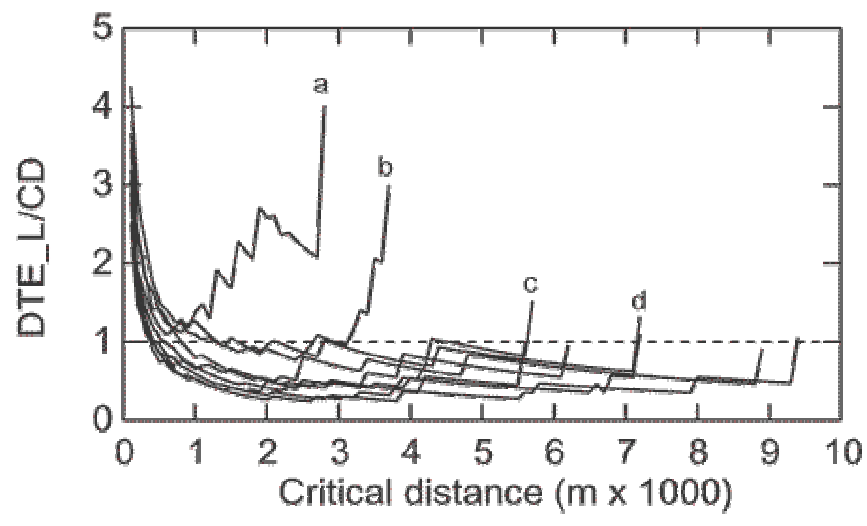

The second critical threshold we identified was a point where $C D=$ DTE_L or the ratio between $C D$ and DTE_L $=1.0$. At MPSR $=2$ ha, DTE_L between harvest patches exceeds the $\mathrm{CD}$ at all points along the curve (i.e., DTE_L/CD > 1.0; Fig. 4). Old-growth patch DTE_L/CD $<1.0$ from $\mathrm{CD}=900 \mathrm{~m}$ to $\mathrm{CD}=$ 4100 , and $>1.0$ at all other CD (Fig. 4). Wildfire patch DTE_L/CD $<1.0$ from $C D=800 \mathrm{~m}$ to $\mathrm{CD}=7800 \mathrm{~m}$, and $>1.0$ at all other CD (Fig. 4). Among individual LUs, only one (Fig. 5a) had values of DTE_L/CD > 1.0 at all CD. All LUs had DTE_L/CD values > 1.0 at low values of $\mathrm{CD}(\mathrm{CD} \leq 400)$. One $\mathrm{LU}$ had DTE_L/CD values $>1.0$ for all CD except between $\mathrm{CD}=1200 \mathrm{~m}$ and $\mathrm{CD}=3000 \mathrm{~m}$ (Fig. 5b). Two landscapes had DTE_L/CD values largely < 1.0, except at maximum CD of $5600 \mathrm{~m}$ and $7200 \mathrm{~m}$ (Fig. $5 c, d)$. Five LUs had DTE_L/CD values $<1.0$ except at $\mathrm{CD} \leq 400$.
ERRATUM. In the original published version of this article, the $\mathrm{x}$ axis title for the bottom graph in Figure 6, was reported to be "Proportion of old-growth in landscape (\%)". The correct $\mathrm{x}$ axis title is "Proportion of old-growth forest harvested (\%)".

Fig. 6. Amount of old-growth forest (top) and old-growth harvest rate (bottom) versus $\delta$ for old-growth forest patches between nine Landscape Units in the Slocan Valley of southeastern British Columbia. $\delta$ is a derived index of landscape connectivity ranging between 0 and 1.0, where high values represent high connectivity among patches.
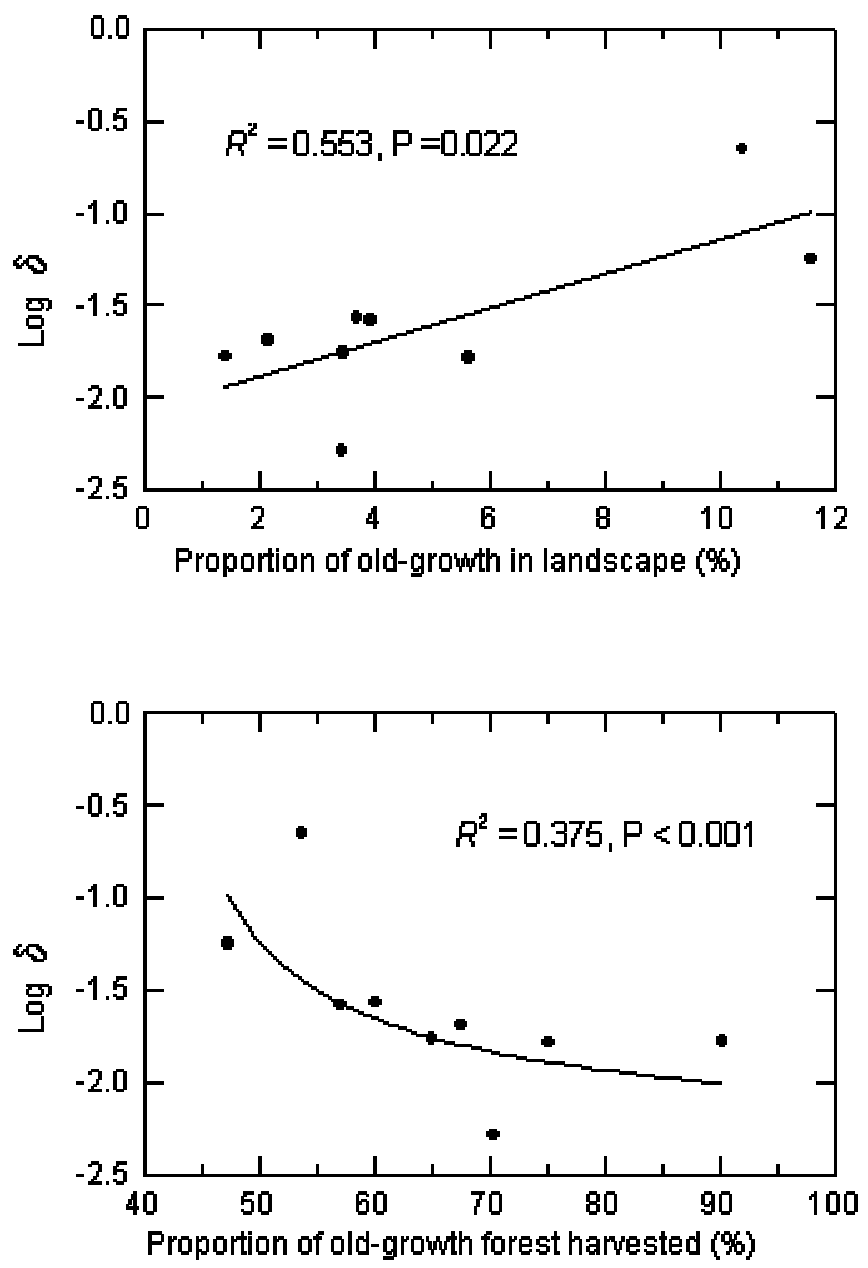

Old-growth patch connectivity among LUs ranged from $\delta=0.1014$ to $\delta=0.5207$ (<mean> $=0.2237$, SE $=0.0405, n=9)$ at MPSR $=2$ ha. Corresponding oldgrowth harvest rates ranged from 47.3 to $90.2 \%$ $(<$ mean $>=65.1 \%, \mathrm{SE}=4.25 \%, n=9$; Fig. 6). Among LUs, we a found significant linear regression between $\delta$ (log transformed) and proportion of old growth in 
the landscape $\left(R^{2}=0.553, P=0.022\right.$; Fig. 6$)$, and a significant curvilinear regression between $\delta(\log$ transformed) and old-growth harvest rate $\left(R^{2}=0.375\right.$, $P<0.001$; Fig. 6).

Table 1. Estimated dispersal abilities and associated landscape availability for selected old growth associates within the Slocan Valley Basin of southeastern British Columbia.

\begin{tabular}{|c|c|c|c|c|c|}
\hline \multirow[b]{2}{*}{ Species } & \multirow[b]{2}{*}{ Weight $(\mathrm{kg})^{1}$} & \multicolumn{2}{|c|}{ Dispersal ability $^{2}$} & \multicolumn{2}{|c|}{$\begin{array}{l}\text { Proportion of landscape accessible } \\
\qquad(\%)^{3}\end{array}$} \\
\hline & & Median (km) & $\begin{array}{l}\text { Probable maximum } \\
\qquad(\mathrm{km})\end{array}$ & $\begin{array}{l}\text { Median } \\
\text { dispersers }\end{array}$ & $\begin{array}{l}\text { Maximum } \\
\text { dispersers }\end{array}$ \\
\hline Northern goshawk & 1.1370 & 17.00 & 192.10 & 100 & 100 \\
\hline Barred owl & 0.5060 & 23.86 & 269.62 & 100 & 100 \\
\hline Boreal owl & 0.1670 & 56.00 & 632.80 & 100 & 100 \\
\hline Great gray owl & 1.3909 & 44.66 & 504.69 & 100 & 100 \\
\hline Hawk owl & 0.2516 & 15.47 & 174.83 & 100 & 100 \\
\hline Saw-whet owl & 0.1072 & 9.12 & 103.02 & 100 & 100 \\
\hline Black-backed woodpecker & 0.0666 & 1.29 & 14.57 & 20 & 100 \\
\hline Three-toed woodpecker & 0.0612 & 1.27 & 14.35 & 20 & 100 \\
\hline Hairy woodpecker & 0.0625 & 1.27 & 14.41 & 20 & 100 \\
\hline Pileated woodpecker & 0.2660 & 1.65 & 18.70 & 24 & 100 \\
\hline Boreal chickadee & 0.0098 & 0.91 & 10.32 & 15 & 100 \\
\hline Mountain chickadee & 0.0101 & 0.92 & 10.38 & 15 & 100 \\
\hline Pygmy nuthatch & 0.0106 & 0.93 & 10.47 & 15 & 100 \\
\hline Red-breasted nuthatch & 0.0098 & 0.91 & 10.32 & 15 & 100 \\
\hline White-breasted nuthatch & 0.0211 & 1.05 & 11.85 & 17 & 100 \\
\hline Brown creeper & 0.0084 & 0.89 & 10.04 & 15 & 100 \\
\hline Northern flying squirrel & 0.1070 & 0.43 & 4.90 & 10 & 70 \\
\hline Marten & 0.6610 & 2.39 & 26.97 & 24 & 100 \\
\hline
\end{tabular}

${ }^{1}$ From Banfield (1974), Eckert (1987), and Dunning (1993). Weights are for females or species average for species without sexual dimorphism.

${ }^{2}$ Derived from available data (northern goshawk and boreal owl) and equations reported in Sutherland et al. (2000). Probable maximum distance is a threshold distance where the probability of a dispersing individual exceeding it is $P<0.001$, and is calculated as median dispersal distance multiplied by 11.3 (Sutherland et al. 2000).

${ }^{3}$ Based on the amount of habitat cluster area available for a given dispersal ability, calculated as a proportion of the landscape size (Fig 7).

Estimated species dispersal distances ranged from 0.43 $\mathrm{km}$ (northern flying squirrel (Glaucomys sabrinus)) to $56.00 \mathrm{~km}$ (boreal owl (Aegolius funereus)) for median dispersal distances with corresponding probable maximum distances of 4.90 and $632.80 \mathrm{~km}$ (Table 1). All species, with the exception of the northern flying squirrel, had the ability to access all old-growth patches in the landscape at maximum dispersal 
distances (Table 1, Fig. 7). Median dispersers, however, were more limited, with only the northern goshawk and owls with median dispersal abilities providing access to $100 \%$ of old-growth patches in the landscape. Smaller birds and mammals, including the marten, were able to access only 10-24\% of the landscape at median dispersal distances (Fig. 7).

Fig. 7. Proportion of the landscape accessible as a function of an organism's ability to move (critical distance) in the Slocan Valley Basin of southeast British Columbia. Shown here are curves for minimum patch size requirements (MPSR) of 2, 12, and 15 ha. Proportion of the landscape was calculated as the proportion of the entire landscape within habitat clusters at each critical distance.

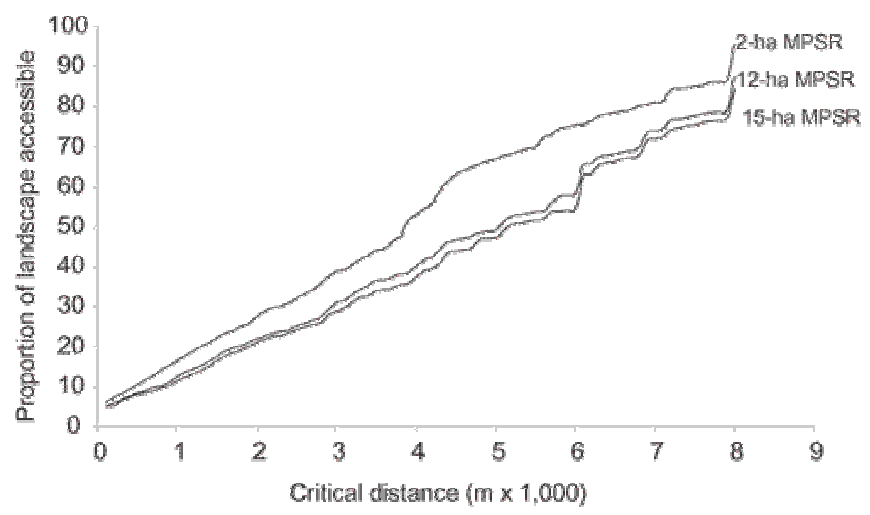

\section{DISCUSSION}

Changes in connectivity for all three patch types were scale dependent, with proportionally larger increases in connectivity attained at high CDs. As theory predicted, critical thresholds, where small changes in pattern produce abrupt responses (Turner and Gardner 1991), were found at relatively high CDs, producing abrupt changes in connectivity until a final threshold was attained where all patches were connected and formed a single cluster (With and Crist 1995, Keitt et al. 1997). Our results are consistent with O'Neill et al. (1988) who, in an application of percolation theory, predicted a relationship between decreasing habitat amount and an organism's ability to traverse nonhabitat that results in the formation of a percolating cluster (a habitat cluster that spans the landscape). In this way, an organism that can cross large distances will be able to use resources that are sparsely dispersed. In our case, abrupt changes in connectivity were attributable to distant patches that, once becoming accessible at high CDs, sharply increased habitat availability. Thresholds, in this case, represented the minimum ability an organism must have to perceive the entire landscape as connected and thereby travel to every patch.

Harvest patches in this landscape were more connected than old-growth patches, which were more connected than wildfire patches, based on relative values of $\delta$. Current harvest patch patterns are particularly important in light of the persistent legacy left by current harvest patterns on future forest patterns (Nelson and Finn 1991, Wallin et al. 1994, Bunnell et al. 1999, Nelson and Wells 2000). This has important implications for future forest patterns that may result from regenerated harvest blocks. If left to attain oldgrowth conditions, current harvest patterns represent a future old-growth forest pattern that is more connected than existing old-growth forest patterns. This dispels the notion that harvest patches may represent a more fragmented patch pattern in such a case (Krummel et al. 1987). Two major caveats, however, are that (1) old-growth stands resulting from regenerated cut blocks may not be of similar quality to existing oldgrowth stands, and (2) regenerated cut blocks in a managed forest may be harvested before attainting oldgrowth structure.

Patch size was not correlated with connectivity because wildfire patches, with the lowest connectivity index, were almost three times larger (mean differences) than harvest and old-growth patches. However, we found strong correlation between connectivity and total patch amount. There were more harvest patches than old-growth patches making up more total patch area, followed by the number and total amount of wildfire patches. As well, individual landscape units displayed an increasing trend in oldgrowth patch connectivity with increasing old-growth amount. Similarly, we found consistent correlation between habitat amount and other landscape indices in this landscape (R. D'Eon, unpublished data). The strong relationship between amount of habitat and connectivity in this case supports the importance of habitat amount in discussions of landscape structure (Fahrig 1997) and the measurement of landscape connectivity (Tishendorf 2001).

Old-growth harvesting was negatively correlated with old-growth connectivity and thus supports a hypothesis that forest harvesting reduced old-growth connectivity in this landscape. However, as connectivity is strongly related to habitat amount in 
this case, the relationship between reduced connectivity with increased harvesting is no doubt related to a reduction in the amount of old growth in the landscape since the onset of commercial forest harvesting. If true, this has important management implications in that, by simply removing total amount of habitat, regardless of spatial configuration of the removal, connectivity within remaining habitat will be reduced. This supports recent assertions that the current forest management focus on spatial configuration of removals, rather than the amount of total removal, is misguided (Fahrig 1999, Trzcinski et al. 1999).

Nonetheless, accepting the view that overall reductions in a habitat type result in lower connectivity between patches of a given habitat type, says little about whether or not remaining patches are connected. As stated, landscapes are not inherently disconnected or not, but must be evaluated from an organismal perspective and at the scale of interaction between the landscape and the organism. It is entirely conceivable that habitat reductions leading to lower connectivity values do not result in a fragmented landscape if an organism does not so perceive it, or vice versa.

At the default MPSR of 2 ha, the minimum critical distance where all patches became connected was lowest for harvest patches $(5400 \mathrm{~m})$ followed by oldgrowth $(8000 \mathrm{~m})$ and wildfire patches $(8400 \mathrm{~m})$. Thus, species associated with early seral habitat provided by harvest blocks and an ability to move $5400 \mathrm{~m}$ through this landscape would perceive the entire landscape as connected and be able to travel to all patches. Similarly, species dependent on old-growth forest or recent wildfire patches would require an ability to travel 8000 or $8500 \mathrm{~m}$, respectively, before viewing the entire landscape as connected.

Among old-growth associates, all species but the northern flying squirrel, have estimated probable maximum natal dispersal abilities in excess of $8000 \mathrm{~m}$. This suggests that at least some individuals of these species seeking new reproductive habitat have the ability to disperse to and inhabit all old-growth patches in this landscape. Although long-distance dispersal is rare (Sutherland et al. 2000, Turchin 1988), maximum dispersal ability has large implications for metapopulation dynamics. In a metapopulation model, it is the ability of some individuals to recolonize distant patches that lowers the probability of local extinctions (Levins 1970). We suggest, therefore, that all old-growth associates we considered, with the exception of the northern flying squirrel, have a low probability of local extinction that is attributable to a lack of connectivity between old-growth patches in this landscape.

Short dispersal distances are more frequent and strongly influence age and sex structure and abundance within populations (Sutherland et al. 2000). Our estimates indicate that only the larger, more vagile, carnivorous birds could access all old-growth patches at median dispersal distances. Median dispersing woodpeckers seeking old-growth structure in this landscape would be limited to approximately $20 \%$, chickadees and nuthatches to approximately $15 \%$ , and marten to $24 \%$ of the landscape. As well, any impacts of reduced landscape access are further exacerbated in that these values represent the sum area within all habitat clusters combined, which are not continuous but inherently isolated from each other by distances in excess of the critical distance.

These findings suggest distribution and abundance of smaller, less vagile species may be affected in this landscape as a consequence of reduced connectivity between old-growth patches. Of particular concern is the northern flying squirrel, which is typically associated with old forest structure for food and denning requirements (Carey et al. 1997). Our results indicate that only $70 \%$ of the landscape is accessible to northern flying squirrels even at maximum dispersal distances, and only $10 \%$ of the landscape at median dispersal distances, if flying squirrels are obligate users of old-growth structure. On this basis, northern flying squirrels may be limited in this landscape by a lack of connectivity between old-growth patches, which has implications for minimum viable population requirements, as individuals are isolated from each other. A caveat, however, to this conclusion is that flying squirrels may be facultative old-growth users (Ransome and Sullivan 1997; D. Ransome, personal communication). If so, effects of dispersed old-growth habitat would be reduced by allowing flying squirrels to use other parts of the landscape, thereby increasing their access to the landscape.

Dispersal and other movements away from a patch of suitable habitat to another suitable patch are generally considered costly because moving individuals may face increased mortality rates associated with a higher predation risk and the physiological costs of moving through unfamiliar or hostile habitat (Sutherland et al. 2000 and references therein). Therefore, individuals that move beyond the limits of available habitat (i.e., 
travel farther than available patches) incur costs associated with moving without the benefit of increased suitable habitat access. This notion is scale dependent and should apply to the scale of the organism and its interaction with the landscape. For example, an organism with an ability to move distances of $500 \mathrm{~m}$ between suitable patches, will incur unreciprocated costs by moving $500 \mathrm{~m}$ from a patch if the next suitable patch is $1000 \mathrm{~m}$ away. Indeed, Keitt et al. (1997) predicted that selection pressure may favor species with dispersal abilities equal to the scale of distances between habitat patches in the landscape because of the optimal balance between the benefits of increased habitat and movement costs.

Among patches in our study area, we used the ratio between DTE_L and the associated CD as a measure of the optimal balance between movement costs and increased habitat access. We identified this optimal balance where DTE_L (a measure of accessible habitat) equaled CD (an organism's ability to move). For old-growth patches within the entire landscape, this optimal balance occurred at $C D=900$ and 4100 $\mathrm{m}$. Values between these two points $(900-4100 \mathrm{~m})$ represent a range of movement ability that exceeds accessible habitat and, therefore, higher movement costs without the benefits of increased habitat access. Conversely, values on either side of this range $(\leq 800$ $\mathrm{m}$ and $\geq 4200 \mathrm{~m}$ ) represent movement abilities that are below accessible habitat and, therefore, movement risks that are rewarded with increased access to habitat. When considering individual landscape units, we found similar patterns, where all landscapes displayed ratios above 1.0 for small CDs $(\leq 400 \mathrm{~m})$, below 1.0 for most intermediate CDs, and near or above 1.0 for relatively high CDs. This suggests that species with either relatively small or large movement abilities in this landscape receive benefits of increased habitat access without unnecessary movement costs; the opposite is true for species with intermediate movement abilities. This is consistent with our predictions that larger, more vagile species will be able to access all patches in this landscape and view it as connected, but smaller species, with intermediate movement abilities, will be more restricted. Presumably, species on the far left of the curve $(\mathrm{CD} \leq$ $400 \mathrm{~m})$ are so restricted by their movement abilities that, once in a suitable habitat patch, they are unlikely to move beyond the habitat cluster and are, therefore, almost always within a suitable habitat cluster.

Minimum patch size requirements produced predictable results: connectivity was reduced between old-growth patches when minimum patch sizes were imposed. As well, the amount of the landscape available to organisms was reduced in a similarly predictable manner. This phenomenon is, again, no doubt related to the ultimate result of patch size constraints that exclude patches from the analyses: a reduction in total habitat amount. Our results in this case are consistent with results from simulations in and predictions from artificial landscapes (Dale et al. 1994, With 1999). However, although intuitively appealing, application of a minimum patch size governing whether or not patches are included in investigations of connectivity in real landscapes, is currently limited. Due to either a demonstrated lack of patch size requirement or a paucity of data, we could justify imposing patch size constraints for only two species on our list of old-growth associates. We caution that a distinction must be made between home range size, for which much data for many species exist, and documented cases of species avoiding the use of patches below a certain size, for which few data exist. The latter distinction is vital to an understanding of use and, therefore, connectivity between patches in real landscapes. And, because the influence of minimum patch size in investigations of connectivity can be large, as demonstrated in this study, we strongly recommend future empirical work include the gathering of data on minimum patch size use.

Our method of measuring landscape connectivity is consistent with recommendations for organismalbased procedures and, very importantly, is a function of the scale at which an organism interacts with the landscape. Although it is not a direct measure of animal movement, it incorporates elements of organism movement at a wide spectrum of scalesunlike most landscape indices in the study of landscape connectivity. More importantly though, we believe a large advantage of our method is its applicability in real landscapes with real organisms, its intuitive simplicity, and its feasibility in practical situations. It is particularly suited, by design, for use with digital forest-cover information in vector format. We suggest this method could be useful for speciesspecific assessments for any habitat type. As well, our measure of connectivity decreased with decreases in habitat amount, unlike other methods in which the opposite is a persistent problem (Tishendrof and Fahrig 2000a).

Although useful for analytical purposes, a major limitation to our method is the assumption of a simplistic binary landscape model, where movement 
between patches is linear and gaps between patches are equally unsuited to every organism. This assumption is likely false to varying degrees in most cases. Indeed, organisms most likely perceive habitat suitability along a gradient and travel along routes that facilitate their movement (Taylor et al. 1993, With et al. 1997). However, the importance of distance between patches, the basis of our methods, is indisputable. Rather, we suggest the shortcomings of a binary landscape model can be reduced by including additional modifications based on empirical data specific to a landscape and species of interest.

Responses to this article can be read online at: http://www.consecol.org/vol6/iss2/art10/responses/index.html

\section{Acknowledgments:}

We are grateful to Slocan Forest Products, Slocan Division, for their financial support and, especially, the efforts of Alex Ferguson. We thank Glenn Sutherland for his assistance with dispersal estimates and comments on a previous draft. Graduate student support to R. D'Eon was provided by the University of British Columbia, Department of Forest Sciences, the National Engineering Research Council of Canada, and a Canfor Corporation fellowship in forest wildlife management.

\section{LITERATURE CITED}

Allen, A. W. 1987. Habitat suitability index models: barred owl. U. S. Fish and Wildlife Service. Biological Report 82, Washington, DC, USA.

Arnold, G. W., D. E. Steven, J. R. Weeldenburg, and E. A. Smith. 1993. Influences of remnant size, spacing pattern and connectivity on population boundaries and demography in euros (Macropus robustus) living in a fragmented landscape. Biological Conservation 64: 219-230.

Banfield, A. W. F. 1974. The mammals of Canada. University of Toronto Press, Toronto, Ontario, Canada.

BC Ministry of Forests and BC Ministry of Environment, Lands and Parks. 1995. Forest practices code biodiversity guidebook. Queen's Printer, Victoria, British Columbia, Canada.

Braumandl, T. F., and M. P. Curran. 1992. A field guide for site identification and interpretation for the Nelson Forest Region. British Columbia Ministry of Forests, Nelson, British Columbia, Canada.
Bunnell, F. L. 2000. Vertebrates and stand structure in the Arrow IFPA. Arrow Innovative Forestry Practices Agreement Technical Report, Slocan, British Columbia, Canada.

Bunnell, F. L., R. W. Wells, J. D. Nelson, and L. L. Kremsater. 1999. Patch sizes, vertebrates, and effects of harvest policy in southeastern British Columbia. Pages 271293 in J. A. Rochelle, L. A. Lehmann, and J. Wisniewski, editors. Forest fragmentation: wildlife and management implications. Koninklijke Brill NV, Leiden, The Netherlands.

Carey, A. B., T. M. Wilson, C. C. Maguire, and B. L. Biswell. 1997. Dens of northern flying squirrels in the Pacific Northwest. Journal of Wildlife Management 61:684699.

Chapin, T. G., D. J. Harrison, and D. D. Katnik. 1998. Influence of landscape pattern on habitat use by American marten in an industrial forest. Conservation Biology 12:1327-1337.

Dale, V. H., S. M. Pearson, H. L. Offerman, and R. V. O'Neill. 1994. Relating patterns of land-use change to faunal biodiversity in the Central Amazon. Conservation Biology 8:1027-1036.

Davidson, C. 1998. Issues in measuring landscape fragmentation. Wildlife Society Bulletin 26:32-37.

Dunning, J. B. 1993. CRC handbook of avian body masses. CRC Press, Boca Raton, Florida, USA.

Eckert, A. W. 1987. The owls of North America. Weathervane, New York, New York, USA.

Fahrig, L. 1997. Relative effects of habitat loss and fragmentation on population extinction. Journal of Wildlife Management 61:603-610.

Fahrig, L. 1999. Forest loss and fragmentation: which has the greater effect on persistence of forest-dwelling animals? Pages 87-95 in J. A. Rochelle, L. A. Lehmann, and J. Wisniewski, editors. Forest fragmentation: wildlife and management implications. Koninklijke Brill NV, Leiden, The Netherlands.

Fahrig, L., and G. Merriam. 1985. Habitat patch connectivity and population survival. Ecology 66: $1762 \& 8211 ; 1768$.

Fahrig, L., and J. Paloheimo. 1988. Determinants of local population size in patchy habitats. Theoretical Population Biology 34:194-213.

Franklin, J. F., and R. T. T. Forman. 1987. Creating landscape patterns by forest cutting: ecological consequences and principles. Landscape Ecology 1:5-18.

Graham, R. T., R. L. Rodriguez, K. M. Paulin, R. L. Player, A. P. Heap, and R. Williams. 1999. The northern 
goshawk in Utah: habitat assessment and management recommendations. General Technical Report RMRS-GTR22. US Department of Agriculture, Forest Service, Rocky Mountain Research Station, Odgen, Utah, USA.

Gustafson, E. J. 1998. Quantifying landscape spatial pattern: what is the state of the art? Ecosystems 1:143-156.

Henein, K., and G. Merriam. 1990. The elements of connectivity where corridor quality is variable. Landscape Ecology 4:157-170.

Keitt, T. H., D. L. Urban, and B. T. Milne. 1997. Detecting critical scales in fragmented landscapes. Conservation Ecology 1(1):4. Available online at URL: http://www.consecol.org/vol1/iss1/art4

Krummel, J. R., R. H. Gardner, G. Sugihara, R.V. O'Neill, and P. R. Coleman. 1987. Landscape patterns in a disturbed environment. Oikos 48:321-324.

Levins, R. 1970. Extinction. Pages 77-107 in M. Gerstenhaber, editor. Lectures on mathematics in the life sciences. Volume 2. American Mathematics Society, Providence, Rhode Island, USA.

Lord, J. M., and D. A. Norton. 1990. Scale and the spatial concept of fragmentation. Conservation Biology 4:197-202.

McGarigal, K., W. H. Romme, M. Crist, and E. Roworth. 2001. Cumulative effects of roads and logging on landscape structure in the San Juan Mountains, Colorado (USA). Landscape Ecology 16:327-349.

Nelson, J. D., and S. T. Finn. 1991. The influence of cutblock size and adjacency rules on harvest levels and road networks. Canadian Journal of Forest Research 5:595-600.

Nelson, J. D., and R. Wells. 2000. The effect of patch size on timber supply and landscape structure. Pages 195-207 in R. G. D'Eon, J. Johnson, and E. A. Ferguson, editors. Ecosystem management of forested landscapes: directions and implementation. UBC Press, Vancouver, British Columbia, Canada.

O'Neill, R. V., B. T. Milne, M. G. Turner, and R. H. Gardner. 1988. Resource utilization scales and landscape pattern. Landscape Ecology 2:63-69.

Pither, J., and Taylor, P. D. 1998. An experimental assessment of landscape connectivity. Oikos 83:166-174.

Ransome, D. B., and T. P. Sullivan. 1997. Food limitation and habitat preference of Glaucomys sabrinus and Tamiasciurus hudsonicus. Journal of Mammalogy 79:538549.

Reynolds, R. T., R. T. Graham, R. M. Hildegard, R. L., Bassett, P. L. Kennedy, D. A. Boyce, Jr., G. Goodwin, R. Smith, and E. L. Fisher. 1992. Management recommendations for the northern goshawk in the southwestern United States. General Technical Report RM-
217. U. S. Department of Agriculture, Forest Service, Rocky Mountain Forest and Range Experiment Station, Ft. Collins, Colorado, USA.

Rowe, J. S. 1972. Forest regions of Canada. Canadian Forestry Service, Department of the Environment, Publication Number 1300, Ottawa, Ontario, Canada.

Schumaker, N. 1996. Using landscape indices to predict habitat connectivity. Ecology 77:1210-1225.

Snyder, J. E., and J. A. Bissonette. 1987. Marten use of clear-cuttings and residual forest stands in western Newfoundland. Canadian Journal of Zoology 65:169-174.

SPSS 1998. SYSTAT 8.0 for Windows. SPSS Inc., Chicago, Illinois, USA.

Stauffer, D., and A. Aharony. 1985. Introduction to percolation theory. Taylor and Francis, London, UK.

Sutherland, G. D., A. S. Harestad, K. Price, and K. P. Lertzman. 2000. Scaling of natal dispersal distances in terrestrial birds and mammals. Conservation Ecology 4(1):16. Available online at URL: http://www.consecol.org/vol4/iss1/art16

Taylor, P. D., L. Fahrig, K. Henein, and G. Merriam. 1993. Connectivity is a vital element of landscape structure. Oikos 68:571-573.

Tishendorf, L. 2001. Can landscape indices predict ecological processes consistently? Landscape Ecology 16:235-254.

Tishendorf, L., and L. Fahrig. 2000a. How should we measure landscape connectivity? Landscape Ecology 15:633-641.

Tishendorf, L., and L. Fahrig. 2000b. On the usage and measurement of landscape connectivity. Oikos 90:7-19.

Trzcinski, M. K., L. Fahrig, and G. Merriam. 1999. Independent effects of forest cover and fragmentation on the distribution of forest breeding birds. Ecological Applications 92:586-593.

Turchin, P. 1988. Quantitative analysis of movement: measuring and modeling population redistribution in animals and plants. Sinauer Associates, Sunderland, Massachusetts, USA.

Turner, M. G., and R. H. Gardner. 1991. Quantitative methods in landscape ecology: an introduction. Pages 3-14 in M. G. Turner and R. H. Gardner, editors. Quantitative methods in landscape ecology. Springer-Verlag, New York, New York, USA.

Wallin, D. O., F. J. Swanson, and B. Marks. 1994. Landscape pattern response to changes in pattern generation rules: land-use legacies in forestry. Ecological Applications 4:569-580. 
Wiens, J. A. 1989. Spatial scaling in ecology. Functional Ecology 3:385-397.

Wiens, J. 1996. Wildlife in patchy environments: metapopulations, mosaics, and management. Pages 53-84 in D. R. McCullough, editor. Metapopulations and wildlife conservation. Island Press, Washington, DC, USA.

With, K. 1997. The application of neutral landscape models in conservation biology. Conservation Biology 5:10691080 .

With, K. 1999. Is landscape connectivity necessary and sufficient for wildlife management? Pages 97-115 in J. A. Rochelle, L. A. Lehmann, and J. Wisniewski, editors. Forest fragmentation: wildlife and management implications. Koninklijke Brill NV, Leiden, The Netherlands.

With, K. A., and T. O. Crist. 1995. Critical thresholds in species' responses to landscape structure. Ecology 76:24462459.

With, K., R. H. Gardner, and M. G. Turner. 1997. Landscape connectivity and population distributions in heterogeneous environments. Oikos 78:151-169. 